Björn A. Afzelius

\title{
Ultrastructure of human nasal epithelium during an episode of coronavirus infection
}

Received: 12 November 1993 / Accepted: 6 January 1994

\begin{abstract}
The nasal epithelium from a young girl was examined by electron microscopy and found to be infected by coronavirus. Virions are seen within and outside the ciliated cells, but not outside or within the goblet cells or other cells of the nasal mucosa. Some virions are located near the microvilli, others in pockets in the apical cell membrane. The cytoplasm contains many small vesicles with a single virion, large apical vesicles containing hundreds of virions, and lysosome-like cytosomes with a moderate number of virions. Some viruslike particles devoid of an electron-dense interior are seen both in the cytosomes and extracellularly. Virus budding was observed in the Golgi apparatus but nowhere else in the cell. The ciliated cells seem not to be destroyed by the viruses, although in many cases the cilia are withdrawn into the cell body. The loss of cilia is likely to cause rhinorrhoea.
\end{abstract}

Key words Coronavirus - Virus budding Nasal cilia $\cdot$ Nasal epithelium

\section{Introduction}

Coronaviruses are considered to account for about $10 \%$ of all cases of common cold (Gwaltney 1985; McIntosh et al. 1974; Stott and Garwes 1990), yet their distribution in the ciliated epithelium and their multiplication there has not been studied, either in an in vitro system or in situ. The same is true of ciliated epithelia infected with viruses of other kinds. Although human nasal and bronchial epithelium have been studied electron microscopically during episodes of common cold (Carson et al. 1985; Giorgi et al. 1992; Rautiainen et al. 1992; Winther et al. 1984), or other viral infections (Cornille et al. 1984; Konradova et al. 1982), the viruses within

\section{B. A. Afzelius}

Department of Ultrastructure Research, Biology Building E4, Stockholm University, S-10691 Stockholm, Sweden the epithelial cells causing the infections seem to have eluded the investigators. Certain changes in the infected ciliated nasal epithelium have been reported, such as a detachment of ciliated cells from the epithelium (Ramphal et al. 1979; Turner et al. 1982; Winther et al. 1984), or a loss of cilia from the ciliated cells (Rautiainen et al. 1992), but the mechanisms by which the viruses cause these effects remain unknown.

Replicating coronaviruses have been studied in some cell cultures, such as human fetal diploid lung cells (Oshiro et al. 1971), human WI-38 cells (Becker et al. 1967; Hamre et al. 1967), canine kidney cells (Takeuchi et al. 1976), feline kidney cells (Everman et al. 1989), feline embryonic lung cells (Beesley and Hitchcock 1982), and chick kidney cells (Chasey and Alexander 1976); these cells are non-ciliated. Virions are recorded in several components within these cells: endoplasmic reticulum, perinuclear cisterna, Golgi apparatus, lysosomes, and cytoplasmic vesicles. Budding viruses have been found in the membrane of the endoplasmic reticulum intruding into its cisternae.

During the last 15 years, I have examined the nasal or bronchial epithelium from several hundred persons with respiratory tract disease, suspected to suffer from the immotile-cilia syndrome (Afzelius 1979). In a single case, the biopsy contained a multitude of virus-infected cells. The viruses have the morphological characteristics of coronavirus and were seen at several sites in the ciliated cells. The infection has apparently caused a loss of most of the cilia from the ciliated cells.

\section{Material and methods}

A 2.5-year-old girl was examined because of her chronic rhinitis and bronchitis. The girl showed no signs of common cold at the time of the biopsy nor, according to the mother, on the days following the biopsy. A brush biopsy (Rutland and Cole 1980) was taken from concha inferior of the nose and immediately immersed in a fixative consisting of $2.5 \%$ glutaraldehyde in $0.1 \mathrm{M}$ cacodylate buffer, $\mathrm{pH} 7.0$. Fixation time in this case was 9 days, followed by post-fixation in $1 \%$ osmium tetroxide in the same buffer. After 
a brief rinse, the sample was dehydrated in ethanol, embedded in an epoxy resin, Agar 100 (Agar Scientific, Cambridge, England), sectioned, and section stained with uranyl acetate and lead citrate. Sections were examined with a JEOL $100 \mathrm{~S}$ electron microscope. No second biopsy was taken, as it was considered to be of no benefit to the patient.

\section{Results}

The nasal epithelium in the examined brush biopsy contained a mixture of ciliated cells and mucus-producing cells in about the same ratio as is found in healthy persons. It is impossible to decide from a brush biopsy whether some ciliated cells have detached from the epithelium as a consequence of the infection, since all brush biopsies will show cell fragments and isolated cells, in addition to a morphologically intact epithelium. However, ciliated cells remained in the epithelium at the time of biopsy in a number that seemed normal.

Some ciliated cells were devoid of virions, others contained a few virions, and still others contained hundreds or thousands of them. In all blocks studied from this subject, a heavily infested cell could be seen side by side with one that had few virions or none. Goblet cells were always free from virions and none were seen in the mucus outside the mucus cells. The basal cells underlying goblet cells and ciliated cells were also devoid of virions, as were leucocytes, mast cells and other migrating cells. The virus thus showed a considerable cell specificity in its association.

Virions were seen at the following sites in the ciliated cell or at its surface: some virions adhered to the microvilli or to the apical cell membrane between microvilli and cilia (Fig. 1). A number of virions can be seen in pockets in the plasma membrane; these pockets may penetrate deeply into the cell body and contain a row of virions (Fig. 2). The apical cytoplasm of some cells had large vesicles that contained a great number of virions. No virions were seen in the rough surfaced endoplasmic reticulum, or in the perinuclear cisterna, or in the nucleus or mitochondria.

All infected cells also contained vesicles with a diameter of $0.1-0.2 \mu \mathrm{m}$, each with a single or a few virions that were embedded in a matrix of medium high electron density (Fig. 3). (An alternative and less likely interpretation of these images is that the vesicles in reality represent cross-sections of deep, winding invaginations of the cell surface and that the virions hence lie in invaginated portions of the extracellular fluid.) Most vesicles were seen in the apical cytoplasm, but some were seen in deeper parts of the cell, in particular in and near the Golgi apparatus.

Some cells (Fig. 4) contained a further virion-containing structure characterized by the following features: large size, 1-4 $\mu \mathrm{m}$; a superficial location in the cell; a great number of contained virions; a matrix of such a low electron density that the club-shaped surface projections of the coronaviruses are clearly visible (Fig. 5). The structures will here be called 'apical vesi- cles'. In a longitudinal section through the cell there may be four or more apical vesicles. Each virion contained electron-dense material, $70-80 \mathrm{~nm}$ in diameter, and was surrounded by a triple-layered membrane. The surface projections (peplomers) are $20 \mathrm{~nm}$ long.

The Golgi zone is the second zone of the cell that contained many virions. It was located just apical to the nucleus and at a depth of about $20-30 \mu \mathrm{m}$ from the free cell surface. Most Golgi cisternae in the infected cells had lateral bulbs with one or a few virions (Fig. 6). It is only at this location where budding viruses were seen: a membrane of the Golgi vacuole then made an invagination and dense material could be seen to be accumulated at the membrane (Fig. 7). Occasionally an electrondense, thread-like material could be seen in the vicinity of such a budding virion; possibly it is nucleocapsid material (Fig. 7).

Cytosomes with a content of viruses or virus-like particles could also be found in the cytoplasm, mainly in the apical half of the cell (Fig. 8). Some particles were compact, whereas others appeared to be empty. These cytosomes may represent lysosomes with virions in varying degrees of degradation. Particles of the same 'empty' type could also be seen in some apical vesicles (Fig. 9) or extracellularly, along the microvilli of the ciliated cell (arrows in Fig. 4).

Although a single cell may contain thousands of virions, mainly in the apical vesicles, there were no signs of the infected cell being moribund or dead; organelles and cytoskeleton rather gave the impression of a cell with intact synthetic activity. However, some degenerative changes could be seen, which affect the cilia. In some cells a single axoneme had migrated into the cell body, whereas the neighbouring cilia remained at the cell surface (Fig. 10).

In other cells all axonemes were relocated to sites within the cell body (Fig. 11), whereas in still other cells the ciliary basal bodies had migrated into the cell and had lost the axonemes (Fig. 12). The apical surface of such cells had microvilli but only few free cilia. Mucus vacuoles could sometimes be seen in the apical cyto-

Fig. 1 Apical portion of a ciliated cell. Virions attach to the microvilli and to the apical cell membrane. Some virions are seen in small vesicles in the apical cytoplasm. $\times 28,000$

Fig. 2 A row of virions inside a membrane invagination. $\times 40,000$

Fig. 3 Apical portion of a ciliated cell in which there are some vesicles containing one or a few virions. Fusion between a vesicle and a so called coated vesicle is marked with an arrow. $\times 50,000$

Fig. 4 Apical portion of a ciliated cell in which there are some large apical vesicles with many virions. Note also (arrow) a number of particles that have the appearance of empty virions $\times 13,000$

Fig. 5 Some virions within an apical vesicle seen at high magnification. Note that the triple-layered membrane of the virion is easily visible within virions that are sectioned equatorially, as are peplomers outside the membrane. $\times 125,000$ 

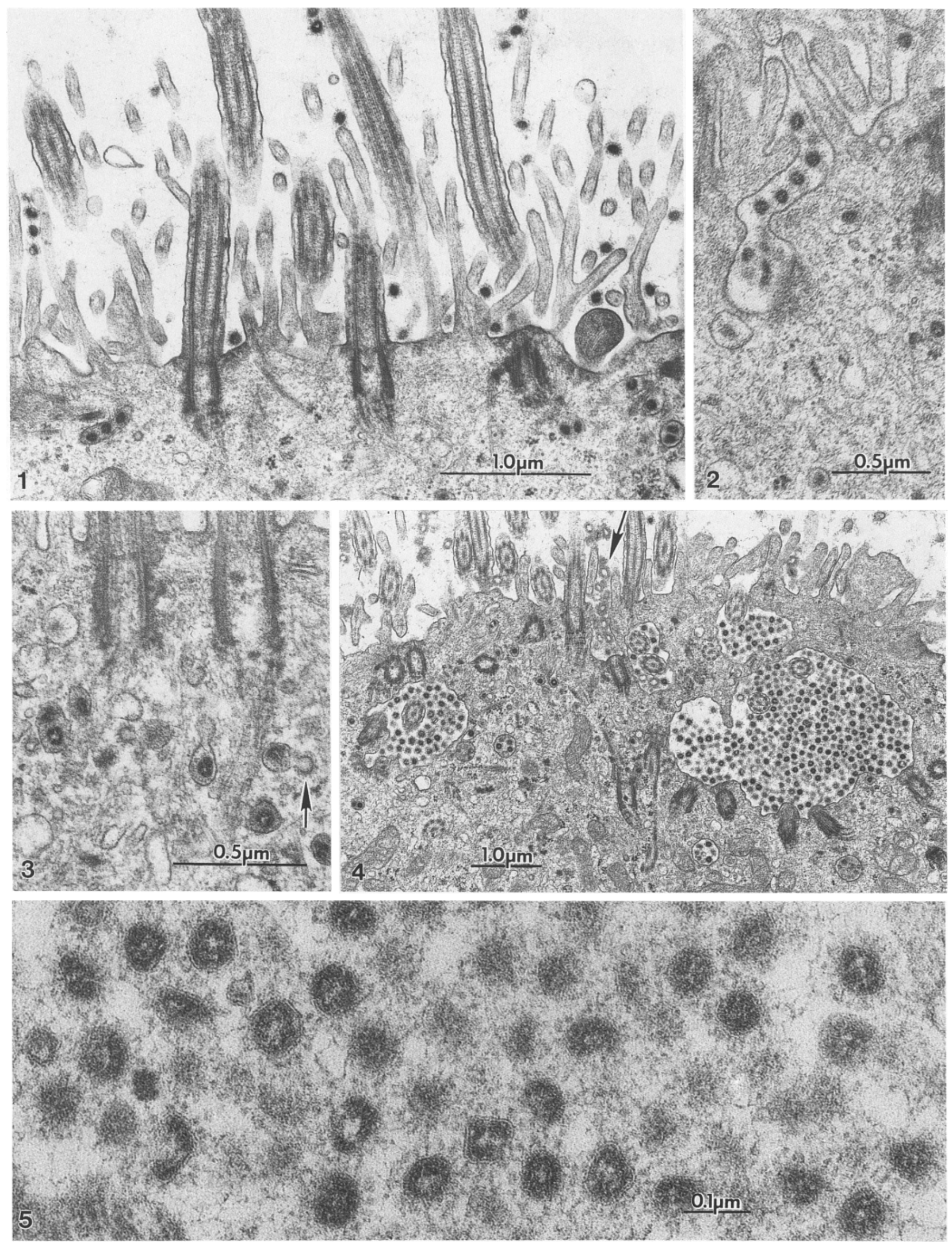


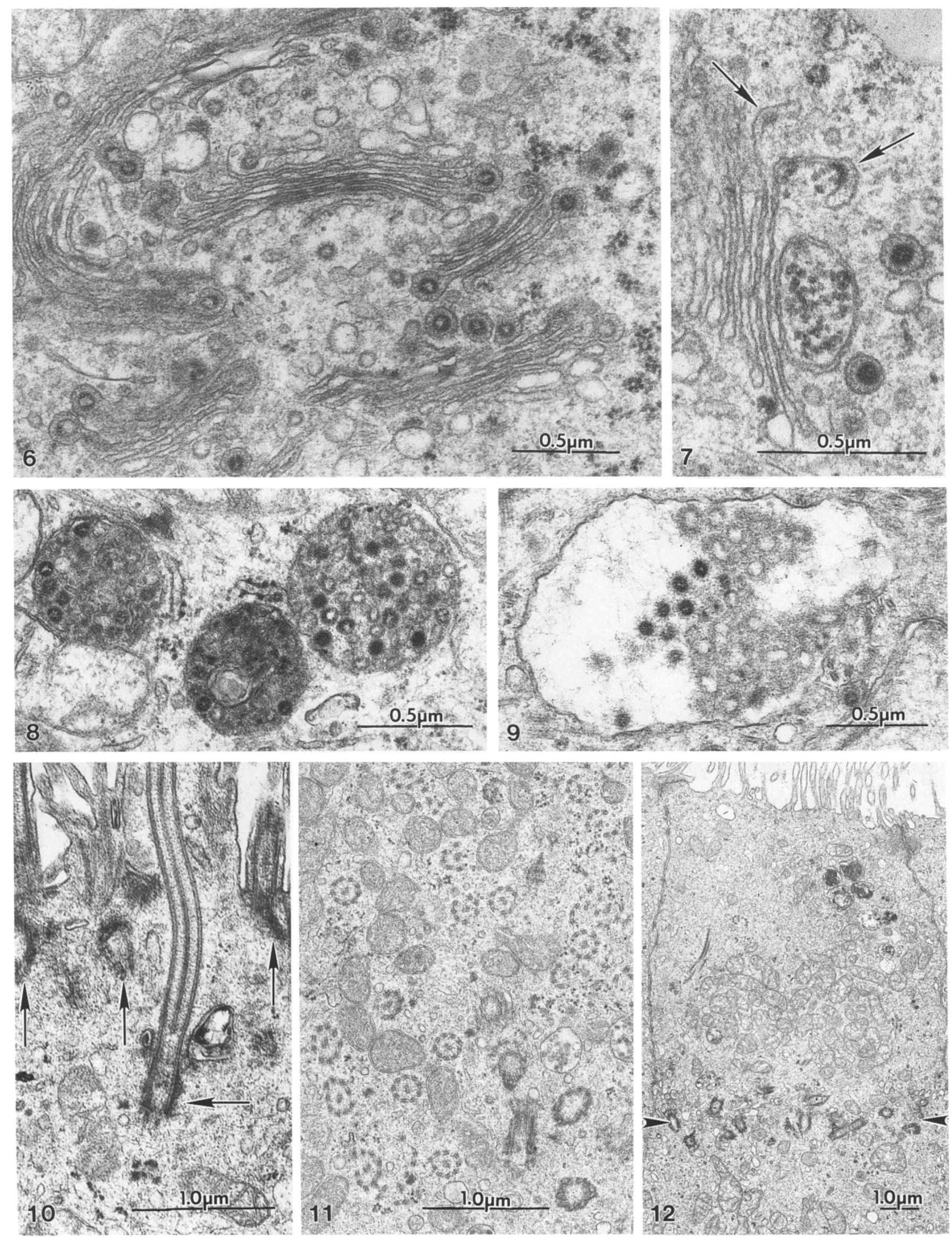


plasm of these cells. They could, however, be distinguished from the goblet cells both by their lacking glycocalyceal bodies in the glycocalyx (Afzelius 1984) and their content of some basal bodies and also of virions, which were never seen in the goblet cells.

\section{Discussion}

The electron micrographs do not permit a rigorous reconstruction of the sequence of events during infections of the nasal epithelium with a coronavirus. Infected cells were a chance finding, rather than the result of a planned experiment or of a study with several consecutive biopsies taken at different stages of an infection. It was thus not possible to use the present material for an immuno-electron microscopical study, which presumably would have given more detailed data on the route of the infecting virus particles and their multiplication.

In studies where the ultrastructural effects of common cold viruses have been examined, no virions have been seen in mucosal cells and isolated virions only have been reported from extracellular sites (Carson et al. 1985; Dourmashkin and Tyrrell 1970). On the other hand, many virions are seen in nasal washings of patients during naturally acquired colds (Larson et al. 1980; McIntosh et al. 1967). I have also attempted to locate virions in the nasal mucosa from some patients during episodes of a common cold but been unable to find any. The reason for these negative results is unknown; the number of virions in the mucosa may be small or their presence of short duration. In contrast, several studies have been published of coronavirus-infected cells in in vitro systems (Becker et al. 1967; Beesley and Hitchcock 1982; Chasey and Alexander 1976; David-Ferreira and Manaker 1965; Everman et al. 1989; Hamre et al. 1967; McIntosh et al. 1967; Os-

Fig. 6 Golgi apparatus in a ciliated cell. Most Golgi vacuoles have bulb-like swollen end sacs containing a virion. $\times 42,000$

Fig. 7 Golgi apparatus with a budding virion (arrows). Note also a coil of electron-dense material surrounded by some membranes. $\times 65,000$

Fig. 8 Three lysosome-like cytosomes which contain virions that appear to be in various stages of degradation. $\times 45,000$

Fig. 9 Apical vesicle with some virions and some virion-like particles that seem to consist of an empty shell only. $\times 40,000$

Fig. 10 Apical portion of a ciliated cell. One cilium has retracted into the cell body (horizontal arrow), whereas its neighbours remain at the surface (vertical arrows) $\times 21,000$

Fig. 11 Cross-section through a ciliated cell in which the cilia have sunk down into the cytoplasm. The $9+2$ structure that characterizes cilia is normally not seen inside the cell body. $\times 30,000$

Fig. 12 A longitudinal section through a ciliated cell, in which the cilia have been lost and their basal bodies (between arrowheads), have sunk down and lie at a layer $7-8 \mu \mathrm{m}$ below the cell surface. $\times 7,500$ hiro et al. 1971), or in an in vivo system (Takeuchi et al. 1976), although none to my knowledge on a ciliated epithelium.

In the present study, cells at different stages - or different degrees of severity - of virus infection have been seen. A possible sequence of events is as follows. Coronaviruses contact the microvilli of the ciliated cell and enter it in apical membrane invaginations. From there they are taken up in small vesicles and transported to the Golgi apparatus, where virus multiplication takes place. They are then transported back to the apical cytoplasm and are stored there in the large apical vesicles before release into the nasal lumen. The formation of the apical vesicles causes the basal bodies to be displaced from the cell surface and to retract into the cell. As a consequence thereof the cells become deciliated and the patient will experience rhinorrhoea. Alternatively, the invading virions are degraded and uncoated in the large apical vesicles before being transported to the Golgi apparatus.

This scheme of virus replication differs somewhat from that seen in studies of cell cultures. Coronavirusinfected cells are reported to contain virions in the perinuclear cisterna and in the endoplasmic reticulum, where they also replicate (Becker et al. 1967; Beesley and Hitchcock 1982; Chasey and Alexander 1976; Hamre et al. 1967; Takeuchi et al. 1976). These compartments were free from virions in the present case and budding was seen only in the Golgi apparatus.

It has also been suspected that a virion (notably a myxovirus) in some way might exploit the sweeping action of a cilium in order to enter the cell (Dourmashkin and Tyrrell 1970). The Hong-Kong virus (a rhabdovirus) is also claimed to adsorb to cilia, although not to enter the cells, in chicken embryo tracheal culture (Blaskovic et al. 1972). The images obtained in the present case rather indicate the microvilli to be the site of a first contact and the apical cell membrane to be the site of viropexia.

In some previous studies of cells infected by coronavirus a 'condensed tubular network' (Oshiro et al. 1971 ) or a 'reticular inclusion' (David-Ferreira and Manaker 1965) has been described and suspected to represent an accumulation of virus precursors. Such tubular aggregates have not been seen in the present case, although occasionally a small coil of electron dense material is seen near the budding virus in the Golgi apparatus.

In conclusion, the coronavirus of the examined patient displayed a strict cell specificity and the virions upon entering the cell were restricted to a few cell compartments only. The virions seem not to have damaged the ciliated epithelium unduly except for a partial deciliation of some cells. 


\section{References}

Afzelius BA (1979) The immotile-cilia syndrome and other ciliary diseases. Int Rev Exp Pathol 19:1-43

Afzelius BA (1984) Glycocalyx and glycocalyceal bodies in the respiratory epithelium of nose and bronchi. Ultrastruct Pathol $7: 1-8$

Becker WB, McIntosh K, Dees JH, Chanock RM (1967) Morphogenesis of avian infectious bronchitis virus and a related human virus (strain 229 E). J Virol 1:1019-1027

Beesley JE, Hitchcock LM (1982) The ultrastructure of feline infectious peritonitis virus in feline embryonic lung cells. J Gen Virol 59:23-28

Blaskovic P, Rhodes AJ, Doane FW, Labzoffsky NA (1972) Infection of chick embryo tracheal organ cultures with influenza A2 (Hong-Kong) virus. Arch Ges Virusforsch 38:250-268

Carson JL, Collier AM, Hu DCS (1985) Acquired ciliary defects in nasal epithelium of children with acute viral upper respiratory infections. N Engl J Med 312:463-468

Chasey JL, Alexander DJ (1976) Morphogenesis of avian infectious bronchitis virus in primary chick kidney cells. Arch Virol 52:101-111

Cornille FJ, Lauweryns JM, Corbeel L (1984) Atypical bronchial cilia in children with recurrent respiratory tract infections - a comparative ultrastructural study. Pathol Res Pract 178:595604

David-Ferreira JF, Manaker RA (1965) An electron microscope study of the development of a mouse hepatitis virus in tissue culture cells. J Cell Biol 24:57-78

Dourmashkin RR, Tyrrell DAJ (1970) Attachment of two myxoviruses to ciliated epithelial cells. J Gen Virol 9:77-88

Everman JF, Heeney JL, McKeirnan AJ, O'Brien SJO (1989) Comparative features of a coronavirus isolated from a cheetah with feline infectious peritonitis. Virus Res 13:15-28

Giorgi PL, Oggiano N, Braga PC, Catassi C, Gabrielli O, Goppa GV, Kantar A (1992) Cilia in children with recurrent upper respiratory tract infections: ultrastructural observations. Pediatr Pulmonol 14:201-205

Gwaltney JM (1985) Virology and immunology of the common cold. Rhinology 23:265-271

Hamre D, Kindig D, Mann J (1967) Growth and intracellular development of a new respiratory virus. J Virol 1:810-816

Hoorn B, Tyrrell DAJ (1969) Organ cultures in virology. Prog Med Virol 11:408-450
Konradova V, Vávrová V, Hlousvová $Z$, Copová $M$, Tománek $A$, Houstek J (1982) Ultrastructure of bronchial epithelium in children with chronic and recurrent respiratory diseases. Eur J Respir Dis 63:516-525

Larson HE, Reed SE, Tyrrell DAJ (1980) Isolation of rhinovirus and coronavirus from 38 colds in adults. J Med Virol 5:221229

Lungarella G, Fonzi L, Ermini G (1983) Abnormalities of bronchial cilia in patients with chronic bronchitis. An ultrastructural and quantitative analysis. Lung 161:147-156

McIntosh K, Dees JH, Becker WB, Kapikian AZ, Chanok RM (1967) Recovery in tracheal organ cultures of novel viruses from patients with respiratory disease. Proc Natl Acad Sci USA 57:933-940

McIntosh K, Chao RK, Krause HE, Wasil R, Mocega HE, Mufson MA (1974) Coronavirus infection in acute lower respiratory tract disease of infants. J Infect Dis 130:502-507

Oshiro LS, Schieble JH, Lennette EH (1971) Electron microscopic studies of coronavirus. J Gen Virol 12:161-168

Ramphal R, Fischlscheiger W, Shands JW, Small PA (1979) Murine influenzal tracheitis: a model for the study of influenza and tracheal epithelial repair. Am Rev Respir Dis 120:1313-1324

Rautiainen M, Kiukaanniemi H, Nuutinen J, Collan Y (1992) Ultrastructural changes in human nasal cilia caused by the common cold and recovery of ciliated epithelium. Ann Otol Rhinol Laryngol 101:982-987

Rutland J, Cole PJ (1980) Non-invasive sampling of nasal cilia for the measurement of beat frequency and study of ultrastructure. Lancet II:564-565

Stott EJ, Garwes DJ (1990) Rhinoviruses adenoviruses and coronaviruses: Their role in respiratory disease. In: Topley WWC, Wilsons GS (eds) Principles in bacteriology, virology, and immunity, vol 4. Arnold, London, pp 243-272

Takeuchi A, Binn LN, Jervis HR, Keenan KP, Hildebrandt PK, Valas RB, Bland FF (1976) Electron microscope study of experimental enteric infection in neonatal dogs with a canine coronavirus. Lab Invest 34:539-549

Turner RB, Hendley JO, Gwaltney JM (1982) Shedding of infected ciliated epithelial cells in rhinovirus colds. J Infect Dis $145: 849-853$

Winther B, Brofeldt S, Christensen B, Mygind N (1984) Light and scanning electron microscopy of nasal biopsy material from patients with naturally acquired colds. Acta Otolaryngol (Stockh) 97:309-318 